\title{
Abnormal spermiogenesis is associated with the X-linked sex-ratio trait in Drosophila simulans
}

\author{
C. MONTCHAMP-MOREAU* \& D. JOLY† \\ */nstitut Jacques Monod, CNRS, Université Paris 7, Dynamique du Génome et Evolution, Tour 42, 4ème étage, \\ 2 Place Jussieu, 75251 Paris cedex 05 and $+C N R S$, Populations, Génétique, Evolution, Avenue de la Terrasse, 91198 \\ Gif sur Yvette cedex, France
}

\begin{abstract}
The sex-ratio trait, known in several Drosophila species, results from X-linked meiotic drive that affects $\mathrm{Y}$-bearing sperm and causes males to produce female-biased progeny. We describe spermiogenesis in three types of $D$. simulans males: wild-type, sex-ratio, and males that bear driver X chromosomes but do not express the sex-ratio trait because of autosomal and Y-linked suppression. Sex-ratio males show numerous spermatid nuclei in abnormal positions throughout their cysts, which occurs rarely, if ever, in the two other types. The degree of the spermiogenic failure in sex-ratio males is correlated with the bias towards females in their progeny. This proves that the trait is a case of meiotic drive and strongly suggests that the abnormal spermatids are Y-bearing ones. The number of cysts per testis, hence the production of $\mathrm{X}$-bearing sperm, is not increased in sex-ratio males. Implications for the spread of the sex-ratio trait in natural populations of $D$. simulans are discussed.
\end{abstract}

Keywords: Drosophila simulans, sex-ratio, spermiogenesis.

\section{Introduction}

The sex-ratio trait is a case of meiotic drive caused by $\mathrm{X}$-linked factors and occurs naturally in several Drosophila species. Males bearing a driver X chromosome, so called sex-ratio males transmit predominantly $\mathrm{X}$-bearing sperm which results in only or mostly female progeny. Sex-ratio males were first described within the subgenus Sophophora, in species belonging to the Drosophila obscura group: D. affinis (Morgan et al., 1925), D. obscura (Gershenson, 1928), D. pseudoobscura, D. persimilis, D. athabasca, D. azteca (Sturtevant \& Dobzhansky, 1936), and D. subobscura (Jungen, 1968). They are also known in unrelated species belonging to the subgenus Drosophila: D. paramelanica (Stalker, 1961), D. mediopunctata (De Carvalho et al., 1989) D. testacea (James \& Jaenike, 1990).

When cytologically investigated, the sex-ratio trait was found to be related to spermatogenic defects (for a review see Lyttle, 1991). In D. subobscura a clear sign of sperm dysfunction is the abnormal position of about half the spermatid nuclei, presumably Y-bearing ones. This occurs in short and long cysts of sex-ratio males in this sperm-heteromorphic

*Correspondence. E-mail: montcha@ccr.jussieu.fr species (Hauschteck-Jungen \& Maurer, 1976). Abnormal behaviour of the Y chromosome during meiosis was described in D. pseudoobscura sex-ratio males (Sturtevant \& Dobzhansky, 1936; Novitsky et al., 1965; Cobbs et al., 1991); however, Y-bearing spermatids are probably eliminated during the individualization process (Policansky \& Ellison, 1970).

In Drosophila simulans, a species of the melanogaster subgroup, which is monomorphic for sperm length (Joly et al., 1989), sex-ratio males were first reported by Faulhaber (1967), who observed abnormal shape but normal position of spermatid nuclei in elongating cysts of these males. Strikingly in this case, the trait appeared to be caused by a recessive autosomal gene. Given that, theoretically, a recessive autosomal sex-ratio driver cannot be selected for, Hurst \& Pomiankowski (1991) suggested that a 'hidden' $\mathrm{X}$-linked driver was in fact responsible for the trait whose expression was suppressed by an autosomal factor. This hypothesis was backed up by the recent report in $D$. simulans of an X-linked sex-ratio trait that is rarely if ever expressed within strains or natural populations because of the presence of autosomal and/or Y-linked suppressors (Merçot et al., 1995; Atlan et al., in press; Montchamp-Moreau et al., in press). The sex-ratio trait described by Faulhaber is expressed at $16^{\circ} \mathrm{C}$ and not at $25^{\circ} \mathrm{C}$ whereas that described by Merçot $e t$ 
al. (1995) is well expressed at the latter temperature. It cannot be excluded that two different sex-ratio systems occur in $D$. simulans.

If sperm are not in limited supply, driver $\mathrm{X}$ chromosomes are transmitted by males at a higher rate than normal $\mathrm{X}$ and consequently are expected to invade the populations rapidly (Gershenson, 1928). However, they are usually found at low frequency in natural populations of Drosophila (Sturtevant \& Dobzhansky, 1936; Dobzhansky \& Epling, 1944; Jungen, 1968; Hauschteck-Jungen, 1990; James \& Jaenike, 1990). A reduced fertility of sex-ratio males is one of the factors that might prevent the spread of driver $\mathrm{X}$ chromosomes. This probably occurs in D. pseudoobscura (Beckenbach, 1978; Wu, 1983a,b). By contrast, in D. subobscura, sex-ratio males produce as many offspring as wildtype males even under multiple mating conditions (Hauschteck-Jungen et al., 1987). The loss of Y-bearing sperm appears to be compensated by an increased production of cysts (Bircher \& Hauschteck-Jungen, 1994).

Here we present data on spermiogenesis related to the X-linked sex-ratio trait in $D$. simulans (Merçot et al., 1995). Driver $\mathrm{X}$ chromosomes in this species were found to occur at high frequency, at least in some island populations, which suggests that the fertility of sex-ratio males in this species is only slightly or not at all reduced (Atlan et al., in press). Our purpose was: (i) first to look for spermiogenesis abnormalities in sex-ratio males and to assess whether these abnormalities were similar to those described by Faulhaber (1967); and (ii) to establish whether the number of cysts was increased in sexratio males, which could promote the spread of driver $\mathrm{X}$ chromosomes in natural populations.

\section{Materials and methods}

\section{D. simulans stocks}

ST: a standard strain, free of driver $\mathrm{X}$ chromosomes and of drive suppressors (Merçot et al., 1995); its Y chromosomes are susceptible to the driver $\mathrm{X}$ chromosomes of the SR strain (see below).

SR: a strain derived from flies collected on Mahé Island, it carries driver sex-ratio $\mathrm{X}$ chromosomes together with autosomal and Y-linked drive suppressors. Thus, SR males do not express the sex-ratio trait and produce equal numbers of male and female progeny (Merçot et al., 1995; Montchamp-Moreau et al., submitted).

SR5: a strain carrying X-linked drive factors from the SR strain, in an ST genetic background. SR5 males express the sex-ratio trait because they do not bear drive suppressors (Montchamp-Moreau et al., in press).
All the experiments were performed at $25^{\circ} \mathrm{C}$ on a cornmeal medium.

\section{Sex-ratio males}

Sex-ratio distortion is expressed in $F_{1}$ males from crosses between ST males and SR or SR5 females $\left(\right.$ denoted as $F_{1}(S R \times S T)$ and $F_{1}(S R 5 \times S T)$, respectively). These males usually produce between 75 per cent and 100 per cent of females in their progeny, and are called sex-ratio males.

\section{Cyst observations}

The testes were dissected in Ringer solution then transferred to a drop of 4',6-Diamidino-2-phenylindole (DAPI) for staining of nuclei. Cysts were allowed to spread out and a coverslip was added. Lengths of cysts were measured at the beginning of individualization, using a video camera connected to a Macintosh computer. We used the public domain NIH IMAGE program (written by Wayne Rasband at the U.S. National Institutes of Health and available from the Internet by anonymous ftp from zyppi.nimh.nih.gov or on floppy disk from NTIS, 5285 Port Royal Rd., Springfield, VA 22161, part number PB93-504868). The DAPI-stained spermatid nuclei in fully (or nearly fully) elongated cysts were counted under a fluorescence microscope after gently squashing the slide. The shape of the nuclei observed varied from lanceolate to needle-shaped corresponding to $\mathrm{P}$ and $\mathrm{Q}$ stages of spermatogenesis (Fuller, 1993, p. 76).

Student's $t$-test was used to compare the mean cyst lengths and the mean numbers of cysts per testis for the different types of males studied. The comparisons of the numbers of spermatid heads per cyst between the different types of males were performed using nonparametric methods.

\section{Cyst abnormalities and distortion strength}

Newly emerged $F_{1}(S R \times S T)$ sex-ratio males were individually mated with virgin ST females and kept together for $48 \mathrm{~h}$ in vials with cornmeal medium. Males were then removed, killed and dissected to determine, as previously described: (i) the number of cysts per testis; and (ii) the number and the localization of spermatid heads in fully elongated cysts. Females were allowed to lay eggs for four additional days. The emerging adults were counted until the vials were exhausted. The sex ratio was established for individual progenies of 50 offspring at least. This parameter shows an extra-binomial variance among sex-ratio males (data not shown), thus the correlations between the distortion strength and (i) the cyst number, and (ii) the number of 
normal spermatids per cyst, were tested using the Spearman rank correlation coefficient.

\section{Results}

\section{Cyst length}

Lengths of fully elongated cysts were measured in $\mathrm{ST}$ and SR males, in sex-ratio $\mathrm{F}_{1}(\mathrm{SR} \times \mathrm{ST})$, and in reciprocal hybrids from the cross between $S T$ females and SR males, denoted as $\mathrm{F}_{1}(\mathrm{ST} \times \mathrm{SR})$. In each case, we observed monomorphism for cyst length. The mean length was obtained from 100 cysts measured on both testes of three males (Table 1). ST males had significantly longer cysts than SR males (Table 2). Cyst lengths were not statistically different between $F_{1}$ males from the two reciprocal crosses, which indicated that the expression of the sex-ratio trait in the $\mathrm{F}_{1}(\mathrm{SR} \times \mathrm{ST})$ males had no effect on cyst length. Moreover, it implied that the difference in cyst length between ST and SR males was not related to the presence of driver chromo-

Table 1 Means and standard errors for cyst length $(N=100)$ and numbers of cysts per testis $(N=50$, one testis per male) for Drosophila simulans ST, SR and $F_{t}$ hybrid males (for the origin of the $F_{1}$ hybrid males the maternal strain is indicated first)

\begin{tabular}{lccc}
\hline & & \multicolumn{2}{c}{ Cyst number/testis } \\
\cline { 3 - 4 } & Cyst length $(\mathrm{mm})$ & $<24 \mathrm{~h}$ & $>48 \mathrm{~h}$ \\
\hline $\mathrm{ST}$ & $1.164 \pm 0.0006$ & $51.98 \pm 1.55$ & $66.80 \pm 2.61$ \\
$\mathrm{SR}$ & $1.145 \pm 0.007$ & $41.84 \pm 1.10$ & $44.36 \pm 1.35$ \\
$\mathrm{~F}_{1}(\mathrm{SR} \times \mathrm{ST})^{*}$ & $1.206 \pm 0.008$ & $47.50 \pm 1.25$ & $59.12 \pm 1.68$ \\
$\mathrm{~F}_{1}(\mathrm{ST} \times \mathrm{SR})$ & $1.206 \pm 0.006$ & $50.22 \pm 1.60$ & $62.70 \pm 2.25$ \\
\hline
\end{tabular}

* Males expressing the sex-ratio trait.

Table $2 P$-values of $t$-tests for cyst length and cyst number comparisons between Drosophila simulans ST, SR and the reciprocal $F_{1}$ hybrid males (for the origin of the $F_{1}$ hybrid males the maternal strain is indicated first)

\begin{tabular}{|c|c|c|c|}
\hline & \multirow{2}{*}{$\begin{array}{l}\text { Cyst length } \\
<24 \mathrm{~h}\end{array}$} & \multicolumn{2}{|c|}{ Cyst number } \\
\hline & & $<24 \mathrm{~h}$ & $>48 \mathrm{~h}$ \\
\hline ST vs. SR & 0.042 & $7.2 \times 10^{-7}$ & $6.4 \times 10^{11}$ \\
\hline $\begin{array}{l}\text { ST vs. } F_{1} \\
(S T \times S R)\end{array}$ & $1.4 \times 10^{6}$ & 0.431 & 0.236 \\
\hline $\begin{array}{l}\text { ST vs. } F_{1} \\
(S R \times S T)\end{array}$ & $4.7 \times 10^{5}$ & 0.026 & 0.015 \\
\hline $\begin{array}{l}\text { SR vs. } F_{1} \\
\quad(S R \times S T)\end{array}$ & $1.9 \times 10^{8}$ & $9.9 \times 10^{4}$ & $7.3 \times 10^{111}$ \\
\hline $\begin{array}{l}\text { SR vs. } F_{1} \\
(S T \times S R)\end{array}$ & $7.5 \times 10$ & $4.3 \times 10^{5}$ & $6.9 \times 10^{1}$ \\
\hline $\begin{array}{c}\mathrm{F}_{1}(\mathrm{ST} \times \mathrm{SR}) \mathrm{vs} . \\
\mathrm{F}_{1}(\mathrm{SR} \times \mathrm{ST})\end{array}$ & 0.949 & 0.183 & 0.236 \\
\hline
\end{tabular}

somes in the latter. On the other hand, both types of $F_{1}$ males had longer cysts than those of the parental strains which suggests an overall heterosis effect.

\section{Number of cysts per testis}

Cysts more than $0.5 \mathrm{~mm}$ length were counted in males less than $24 \mathrm{~h}$ old and in males between 48 and $72 \mathrm{~h}$ old (Table 1). The number of cysts per testis in $\mathrm{ST}, \mathrm{F}_{1}(\mathrm{SR} \times \mathrm{ST})$ and $\mathrm{F}_{1}(\mathrm{ST} \times \mathrm{SR})$ males increased significantly between 24 and $48 \mathrm{~h} \quad\left(t_{98}=4.887, \quad P<0.001 ; t_{98}=5.557, \quad P<0.001\right.$; $t_{98}=4.523, P<0.001$, respectively). It also increased, but not significantly, in SR males $\left(t_{98}=1.445\right.$, $P=0.15)$. ST males had significantly more cysts per testis than SR ones, regardless of age (Table 2). At both ages $F_{1}$ males from the two reciprocal crosses showed intermediate numbers of cysts and did not differ significantly from each other. Thus, the difference in cyst number between ST and SR males was not related to the presence of driver chromosomes in the latter. There was no correlation between the number of cysts per testis and the distorting ability of 40 sex-ratio males (Spearman rank correlation coefficient $r_{s 38}=0.197, P=0.22$ ).

\section{Abnormal spermatids in sex-ratio males}

In $D$. simulans, a cyst normally contains $32 \mathrm{Y}$ - and 32 $\mathrm{X}$-bearing spermatids. In ST males, 70 per cent of the 50 elongated cysts observed had the proper number of heads (64) in the normal (anterior) position (Fig. 1a). In the other cysts (30 per cent), at most one or two heads were lacking, and in one cyst two heads were located in the tail region (Table 3). Similarly, 86 per cent and 82 per cent of the cysts from the $\mathrm{SR}$ and $\mathrm{F}_{1}(\mathrm{ST} \times \mathrm{SR})$ males appeared normal. The others showed slight defects similar to those of ST males, except for one cyst from one SR male that showed numerous heads (21) in the tail region. Finally, with respect to the numbers of misplaced heads, the three types of non sex-ratio males were not statistically different (Smirnov test, $P>0.05)$. By contrast, in all three types of sex-ratio males, $\mathrm{F}_{1}(\mathrm{SR} \times \mathrm{ST})<24 \mathrm{~h}, \mathrm{~F}_{1}(\mathrm{SR} \times \mathrm{ST})>48 \mathrm{~h}$ and $\mathrm{F}_{1} \quad(\mathrm{SR} 5 \times \mathrm{ST})$, numerous heads were repeatedly found in the tail region (Fig. 1b). Misplaced heads occurred in 82 to 100 per cent of the cysts and their number varied widely between cysts (Table 3 ). They are significantly more numerous in the three types of sex-ratio males than in the non sex-ratio ones (Smirnov test, $P<0.001$ ). The numbers of heads in the tail region were not statistically different between the two types of sex-ratio males less than 24 h-old (Smirnov test, $P>0.05$ ), but sex-ratio males more than 48 h-old appeared significantly less affec- 
ted when compared with both $\mathrm{F}_{1}(\mathrm{SR} \times \mathrm{ST})<24 \mathrm{~h}$ (Smirnov test, $P<0.05)$ and $\mathrm{F}_{1}(\mathrm{SR} 5 \times \mathrm{ST})<24 \mathrm{~h}$ (Smirnov test, $P<0.001$ ).

With respect to the total number of heads per cyst, no significant difference was found between the three types of non sex-ratio males (Smirnov tests, $P>0.05)$. The three types of sex-ratio males showed significantly lower numbers of heads per cyst when compared with non sex-ratio ones (Smirnov tests,
$P<0.01)$. Again, sex-ratio males more than 48 h-old were less affected when compared with both $\mathrm{F}_{1}$ $(\mathrm{SR} \times \mathrm{ST})<24 \mathrm{~h}$ and $\mathrm{F}_{1}(\mathrm{SR} 5 \times \mathrm{ST})<24 \mathrm{~h}($ Smirnov tests, $P<0.01$ ).

Within a cyst of a sex-ratio male, heads in the normal position did not show any peculiar heterogeneity for condensation or elongation of nuclei, when compared to those of ST males (Fig. 1a,b), but nuclei in the tail region frequently showed a lesser
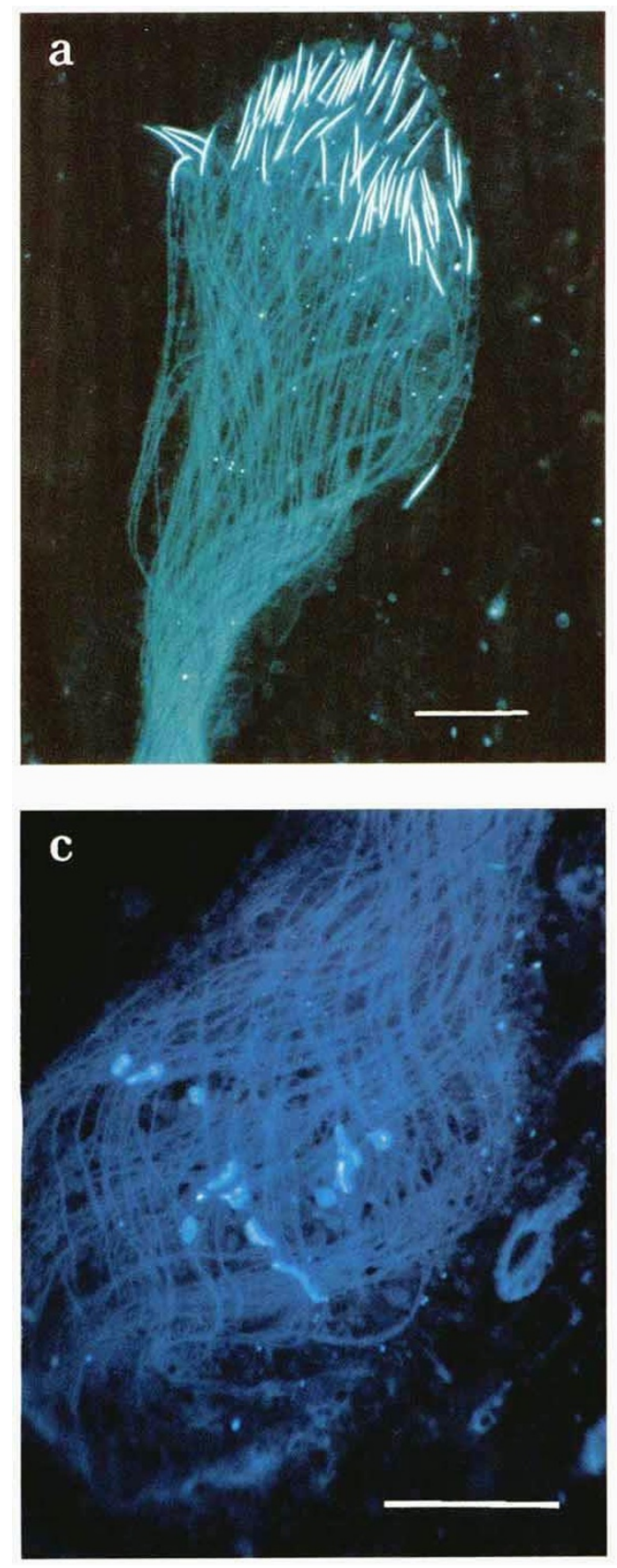
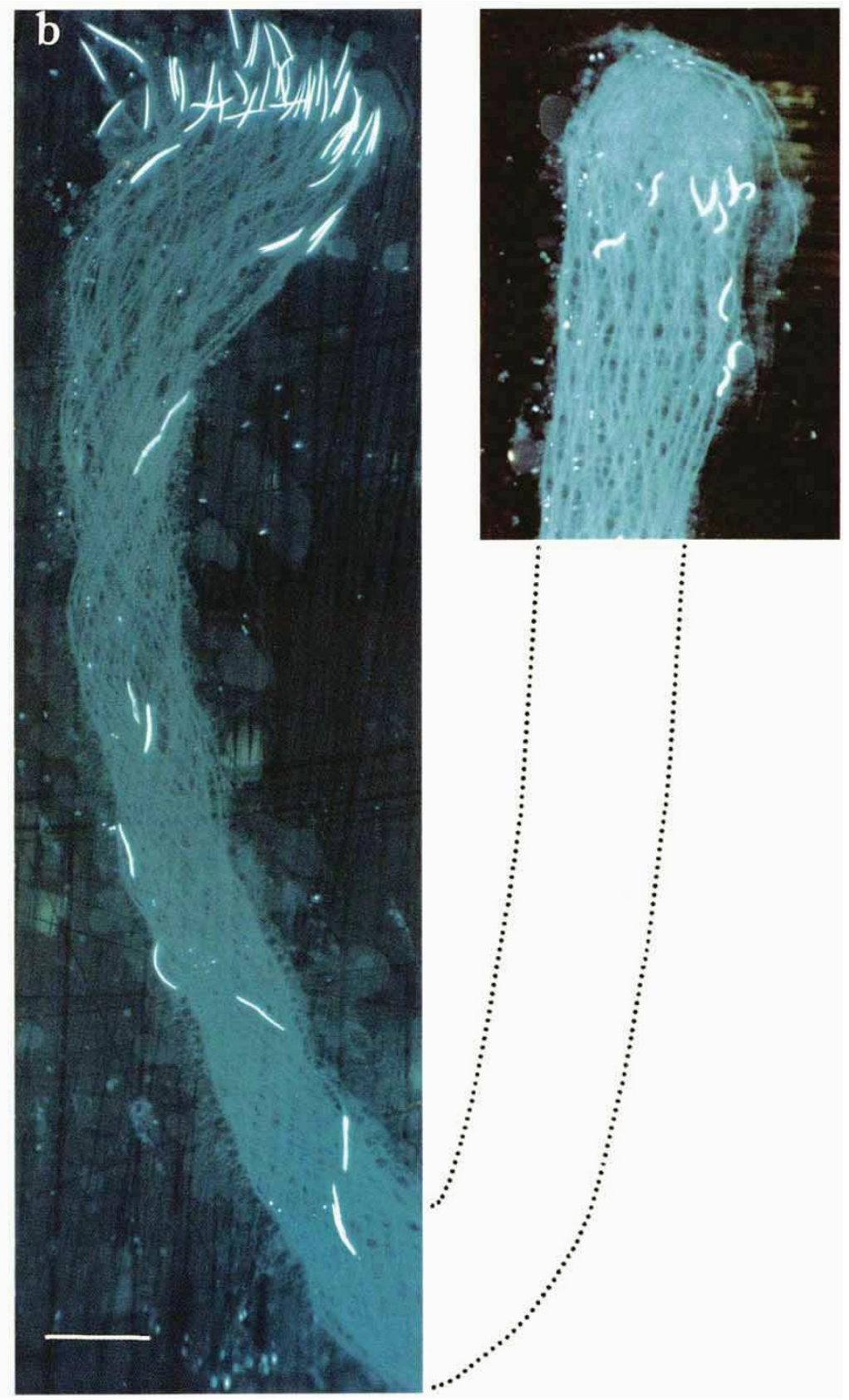

Fig. 1 Fully elongated cysts of Drosophila simulans stained with 4',6-Diamidino-2-phenylindole (DAPI). (a) Cyst of ST male with 64 heads in normal position. (b) Cyst of sex-ratio male, showing heads in anterior and tail regions. (c) Posterior end of a cyst of sex-ratio male with degenerating spermatid nuclei. The bars represent $30 \mu \mathrm{m}$. 
Table 3 Mean numbers of heads in the anterior and tail regions per fully elongated cyst in Drosophila simulans ST, SR and $F_{1}$ hybrids (for the origin of the $F_{1}$ maternal strain is indicated first). For SR5 strain see Materials and methods section. $\mathrm{SE}=$ standard error; minimum and maximum numbers of heads are given within parentheses. For each type of male, 50 cysts were examined on 10 males

\begin{tabular}{|c|c|c|c|c|c|c|}
\hline & \multicolumn{2}{|c|}{ Anterior region } & \multicolumn{2}{|c|}{ Tail region } & \multicolumn{2}{|c|}{ Total } \\
\hline & Mean \pm SE & $(\operatorname{Min}-\max )$ & Mean $\pm S E$ & $(\operatorname{Min}-\max )$ & Mean \pm SE & $(\operatorname{Min}-\max )$ \\
\hline $\mathrm{ST}<24 \mathrm{~h}$ & $63.56 \pm 0.104$ & $(62-64)$ & $0.04 \pm 0.040$ & $(0-2)$ & $63.60 \pm 0.099$ & $(62-64)$ \\
\hline $\mathrm{SR}<24 \mathrm{~h}$ & $63.48 \pm 0.422$ & $(43-65)$ & $0.46 \pm 0.421$ & $(0-21)$ & $63.94 \pm 0.044$ & $(63-65)$ \\
\hline $\mathrm{F}_{1}(\mathrm{ST} \times \mathrm{SR})<24 \mathrm{~h}$ & $63.68 \pm 0.116$ & $(60-64)$ & $0.10 \pm 0.052$ & $(0-2)$ & $63.78 \pm 0.082$ & $(61-64)$ \\
\hline $\mathrm{F}_{1}(\mathrm{SR} \times \mathrm{ST})<24 \mathrm{~h}^{*}$ & $45.50 \pm 1.452$ & $(19-64)$ & $13.74 \pm 1.292$ & $(0-41)$ & $59.24 \pm 0.790$ & $(40-65)$ \\
\hline $\mathrm{F}_{1}(\mathrm{SR} 5 \times \mathrm{ST})<24 \mathrm{~h}^{*}$ & $44.62 \pm 0.901$ & $(32-57)$ & $15.20 \pm 0.836$ & $(5-28)$ & $59.82 \pm 0.502$ & $(50-64)$ \\
\hline $\mathrm{F}_{1}(\mathrm{SR} \times \mathrm{ST})>48 \mathrm{~h}^{*}$ & $53.80 \pm 0.984$ & $(38-64)$ & $8.48 \pm 0.987$ & $(0-24)$ & $62.28 \pm 0.282$ & $(56-64)$ \\
\hline
\end{tabular}

*Males expressing the sex-ratio trait.

degree of condensation and/or elongation, and sometimes signs of degeneration (Fig. 1c).

\section{Abnormal spermatids and distortion strength}

We examined 21 sex-ratio males for their distorting ability and the position of the spermatid heads in 10 fully elongated cysts per male. The number of heads in the normal (anterior) position varied widely between cysts from the same male (data not shown). The largest variation was for a male that showed one cyst with all 64 heads, and another cyst with only 35 heads, in the anterior position. However, the between-male variations were significantly wider than the within-male ones (Kruskal-Wallis one-way analysis of variance by ranks: $\chi_{20}^{2}=61.89$, $P=3.6 \times 10^{-6}$ ).

We tested the correlation between the extent of spermiogenic failure and the distorting ability of the 21 sex-ratio males. They had between 71 and 98 per cent of females in their progeny and the mean number of heads in the anterior position was between 34.4 and 60.8 , depending on the male. A significant negative correlation was found between these two parameters (Fig. 2, Spearman rank correlation coefficient $\left.r_{s 19}=-0.695, \quad P<0.001\right)$. This strongly suggests that the abnormal spermatids are Y-bearing ones and will degenerate. Under this hypothesis, the expected frequency of females in the progeny of a sex-ratio male can be deduced from the mean number $(n)$ of heads in the normal position in its cysts (Lyttle et al., 1986): 32 are assumed to be $\mathrm{X}$-bearing and $(32-n) \mathrm{Y}$-bearing. Thus the expected frequency of females in the progeny is $32 / n$, which corresponds to the regression slope in Fig. 2. All of the experimental points lie upon this slope, which means that some of the normal looking spermatids were nevertheless defective.

\section{Discussion}

\section{Spermiogenic failure}

The X-linked sex-ratio trait in $D$. simulans appeared to be associated with the presence of numerous spermatid heads in the tail region of the cysts, and with a reduced number of total spermatids per cyst. This spermiogenic failure, similar to that reported in D. subobscura sex-ratio males (Hauschteck-Jungen \& Maurer, 1976), definitively indicates that the trait results from meiotic drive. We observed abnormal spermatids in $F_{1}(\mathrm{SR} \times \mathrm{ST})$ and $\mathrm{F}_{1}(\mathrm{SR} 5 \times \mathrm{ST})$ sex-ratio males. The former bear driver $\mathrm{X}$ chromosomes from the SR strain, $Y$ chromosomes from the ST strain and autosomes from both strains, whereas the $\mathrm{F}_{1}(\mathrm{SR} 5 \times \mathrm{ST})$ males carry an ST genetic background except for the X-linked drive factors that come from the SR strain. It follows that abnormal spermiogenesis does result from the presence of the X-linked drive loci themselves and not from other elements of the driver $\mathrm{X}$ chromosomes. This is in accordance with the correlation observed between the degree of spermiogenic failure and the bias towards females.

We rarely observed spermiogenic failure in SR males. This is consistent with the fact that SR males bear driver $\mathrm{X}$-chromosomes but rarely if ever express the sex-ratio trait, usually producing progeny with equal sex ratio (Merçot et al., 1995). This indicates that autosomal and Y-linked factors that prevent the expression of the trait in SR males act as suppressors. This contrasts with the male sex-ratio modifying genes described in $D$. pseudoobscura which induce spermiogenic failure and suppress the trait by an overproduction of sterile $\mathrm{XO}$ males (Cobbs, 1987; Cobbs et al., 1991).

The observed excess of females in the progeny of sex-ratio males is always higher than expected from 


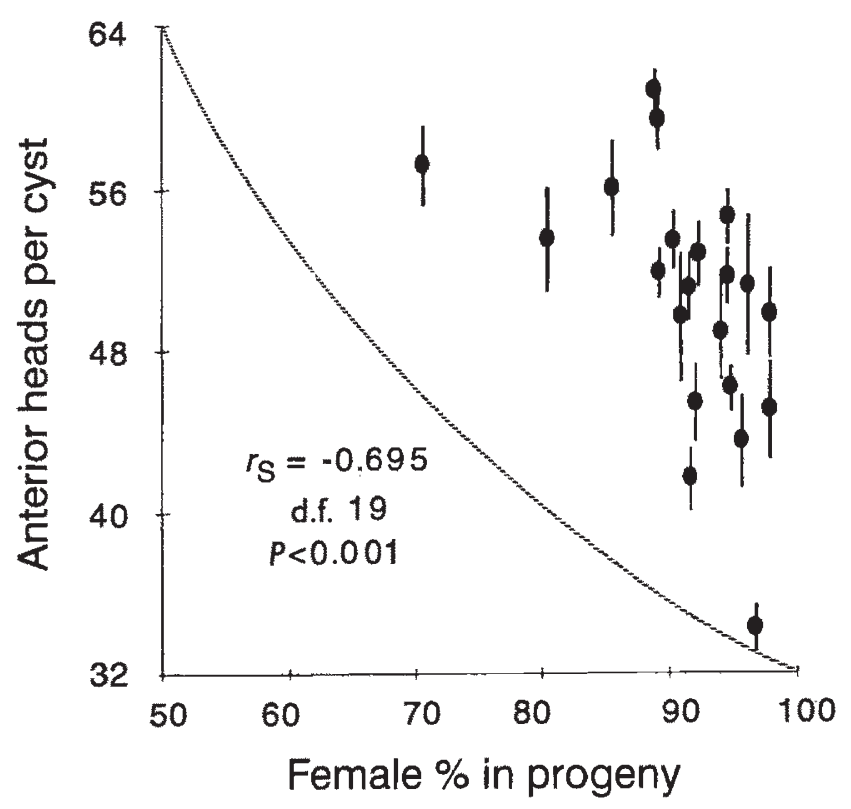

Fig. 2 Mean number of anterior heads per cyst in 21 sex-ratio males of Drosophila simulans (calculated on 10 cysts per male) plotted against female percentage in their progeny. Vertical bars represent the standard error.

the observed spermatid defects. Thus, some of the normal-looking spermatids must be defective. Abnormal or lacking spermatids are significantly more numerous in newly emerged than in sexually mature sex-ratio males. However, we did not detect any age effect on the percentage of females among the progeny of sex-ratio males (unpublished data). Thus, increased spermiogenic failure observed in newly emerged males may rather be related to a delayed sexual maturity. In addition, in newly emerged sex-ratio males, fewer than 32 heads in the normal position were found in three among the 50 cysts observed (Table 3 ). This suggests that the $\mathrm{X}$-bearing sperm must also be affected, to a lesser extent, by the sex-ratio trait and that abnormal spermatids might be only a by-product of the meiotic drive. Alternatively another independent phenomenon might be responsible for the extensive degeneration of the spermatids observed in some cysts. Similar failure of more than half of the spermatids in a cyst occasionally occurs in $D$. subobscura sex-ratio males (Hauschteck-Jungen \& Maurer, 1976).

The sex-ratio trait we described here in $D$. simulans is cytologically different from that described in the same species by Faulhaber (1967). The most striking cytological feature described by this author was a within-cyst dimorphism of spermatid nuclei, whereas he did not report any abnormal position of spermatid heads. In our case, the spermatid heads in the normal position within a cyst of a sex-ratio male do not show any peculiar morphological heterogeneity when compared to those of ST males. By contrast, heads in the tail region frequently show a lesser degree of condensation and/or elongation, and sometimes signs of degeneration. This is an additional similarity to the spermiogenic failure described in D. subobscura sex-ratio males (Hauschteck-Jungen \& Maurer, 1976). The sex-ratio trait described as autosomal by Faulhaber is possibly X-linked (Hurst \& Pomiankowski, 1991), but it differs from ours both by its thermosensibility and by its cytology. Therefore we can conclude that at least two different sex-ratio systems occur in $D$. simulans.

\section{Maintenance of the sex-ratio trait in natural populations of $\mathrm{D}$. simulans}

The fertility of sex-ratio males is one of the factors that determine the fate of the trait, which will spread through populations only if sex-ratio males produce more female progeny than non sex-ratio ones. This must be the case in $D$. simulans, where driver $\mathrm{X}$ chromosomes are widespread, sometimes at a high frequency, and have induced the selection of suppressors which almost completely prevent drive expression (Merçot et al., 1995; Atlan et al., in press). We did not detect any significant effect of meiotic drive X-linked factors on cyst number or cyst length, which implies that sex-ratio and non sex-ratio males do produce roughly equal quantities of $X$ sperm. A higher production of females by sex-ratio males can then be achieved if sperm production is not a limiting factor for sex-ratio male fertility in this species. Data on the sibling species $D$. melanogaster support this hypothesis (reviewed in Gromko et al., 1984; discussed in Beckenbach, 1978).

Our results show that the sex-ratio trait in Drosophila might spread according to different selective processes depending on the opportunities offered by the species. From data on the obscura group species, Bircher et al. (1995) proposed that the prerequisite for the development of the sex-ratio trait in a population may have been the existence of sperm heteromorphism. Indeed, in D. subobscura, the testes of sex-ratio males contain twice as many cysts as those of controls (Bircher \& Hauschteck-Jungen, 1994), via an increased production of short cysts at the expense of long cysts (Bircher et al., 1995). In this species the trait is associated with chromosomal inversions spanning the $\mathrm{X}$ chromosome and thus females homozygous for driver $\mathrm{X}$ chromosomes are expected to have a low fitness (Curtsinger \& Feldman, 1980). In addition, the sperm production 
is possibly a limiting factor for male fertility (Beckenbach, 1978; Hauschteck-Jungen et al., 1987). It follows that an increase in sperm production may be necessary for the sex-ratio trait to evolve in $D$. subobscura, which is not the case in $D$. simulans where it has spread despite the lack of sperm length heteromorphism.

\section{Acknowledgements}

We thank Dr F. Lemeunier who gave us the run of her photomicrographic device, C. Landre for technical assistance and D. Poinsot for helpful comments on the manuscript.

\section{References}

ATLAN, A., MERÇOT, H., LANDRE, C. AND MONTCHAMPMOREAu, C. The sex-ratio trait in Drosophila simulans: geographic distribution of distortion and resistance. Evolution (in press).

BeCKEnBaCH, A. т. 1978. The 'sex ratio' trait in Drosophila pseudoobscura: fertility relations of males and meiotic drive. Am. Nat., 112, 97-117.

BIRCHER, U. AND HAUSCHTECK-JUNGEN, E. 1994. The effect of the Drosophila $X$ chromosome on the number of germ cells. Invert. Reprod. Develop., 25, 159-166.

BIRCHER, U., JUNGEN, H., BURCH, R. AND HAUSCHTECKJUNGEN, E. 1995. Multiple morphs of sperm were required for the evolution of the Sex Ratio trait in Drosophila. J. Evol. Biol., 8, 575-588.

COBBS, G. 1987. Modifier genes of the sex-ratio trait in Drosophila pseudoobscura. Genetics, 116, 275-283.

COBBS, G., JEWELL, L. AND GORDON, L. 1991. Male-sex-ratio trait in Drosophila pseudoobscura: frequency of autosomal aneuploid sperm. Genetics, 127, 381-390.

CURTSINGER, J. W. AND FELDMAN, M. w. 1980. Experimental and theoretical analysis of the sex-ratio polymorphism in Drosophila pseudoobscura. Genetics, 94, 445-466.

DE CARVAlho, A. B., PEIXOTO, A. A. AND Kl.ACZKO, L. B. 1989. Sex-ratio in Drosophila mediopunctata. Heredity, 71, 546-551.

DOBZHANSKy, T. AND EPLING, C. 1944. Contributions to the Genetics, Taxonomy and Ecology of Drosophila pseudoobscura and its Relatives. Publication no. 554. Carnegie Institute of Washington.

Faulhaber, S. H. 1967. An abnormal sex-ratio in Drosophila simulans. Genetics, 56, 189-213.

Fuller, M. T. 1993. Spermatogenesis. In: Bate, M. and Martinez Arias, A. (eds) The Development of Drosophila melanogaster, vol. 1, pp. 71-148. Cold Spring Harbor Laboratory Press, Cold Spring Harbor, NY.

GERSHENSON, s. 1928. A new sex-ratio abnormality in Drosophila obscura. Genetics, 13, 488-507.

GROMKO, M. H., GILBERT, D. G. AND RICHMOND, R. C. 1984. Sperm transfer and use in the multiple mating system of Drosophila. In: Smith, R. L. (ed.) Sperm Competition and the Evolution of Animal Mating Systems, pp. 371-426. Academic Press, Orlando, FL.

HAUSCHTECK-JUNGEN, E. 1990. Post-mating reproductive isolation and modification of the sex-ratio trait in Drosophila pseudoobscura induced by the sex-chromosome gene arrangement $\mathrm{A}_{2+3+5+7}$. Genetica, 83, 31-44.

HAUSCHTECK-JUNGEN, E. AND MAURER, B. 1976. Sperm dysfunction in sex-ratio males of Drosophila subobscura. Genetica, 46, 459-477.

HAUSCHTECK-JUNGEN, E., BURKARD, W., JUNGEN, H. AND BURCH-SCHWALLER, R. 1987. The loss of $Y$-sperm in 'sex ratio' (SR) males of Drosophila subobscura is compensated. Genetica, 74, 27-30.

HURST, L. D. AND POMIANKOWSKI, A. 1991. Causes of sex ratio bias may account for unisexual sterility in hybrids: a new explanation of Haldane's rule and related phenomena. Genetics, 128, 841-858.

iames, A. C. ANd Jaenike, J. 1990. Sex-ratio in Drosophila testacea. Genetics, 126, 651-656.

JOLY, D., CARIOU, M.-L., LACHAISE, D. AND DAVID, J. R. 1989. Variation of sperm length and heteromorphism in Drosophilid species. Génét. Sél. Évol., 21, 283-293.

Jungen, H. 1968. Sex ratio in natuerlichen Populationen von Drosophila subobscura. Arch. Julius Klaus-Stift. VererbForsch, 43, 52-57.

Lyitile, r. w. 1991. Segregation distorters. Ann. Rev. Genet., 25, 511-557.

1.YITI.E, T. W., BRITTNACHER, J. G. AND GANETZKY, B. 1986. Detection of Rsp and modifier variation in the meiotic drive system segregation distorter (SD) of Drosophila melanogaster. Genetics, 114, 183-202.

MERÇOT, H., ATLAN, A., JACQUES, M. AND MONTCHAMPmoreau, C. 1995. Sex-ratio distortion in Drosophila simulans: co-occurrence of a meiotic drive and a suppressor of drive. J. Evol. Biol., 8, 283-300.

MONTChAMP-MOREAU, C., CAZEMAJOR, M. AND LANDRÉ, C. The sex-ratio trait in Drosophila simulans: genetic analysis of distortion and suppression (submitted to Genetics).

MORGAN, T. H., BRIDGES, C. B. AND STUR'TEVANT, T. 1925. The genetics of Drosophila. Bibliogr. Genet., 2, 1-262.

NOVITSKI, E., PEACOCK, w. J. AND ENGEL, J. 1965. Cytological basis of 'sex ratio' in Drosophila pseudoobscura. Science, 148, 516-517.

POLICANSKy, D. AND Ellison, J. 1970. 'Sex ratio' in Drosophila pseudoobscura: spermiogenic failure. Science, $\mathbf{1 6 9}$, 888-889.

STALKER, H. D. 1961. The genetic systems modifying meiotic drive in Drosophila paramelanica. Genetics, 46, 177-202.

STURTEVANT, A. H. AND DOBZHANSky, T. 1936. Geographical distribution and cytology of sex-ratio in Drosophila pseudoobscura and related species. Genetics, 21, 473-490.

wU, C.-I. 1983a. Virility deficiency and the sex-ratio trait in Drosophila pseudoobscura. I. Sperm displacement and sexual selection. Genetics, 105, 651-662.

wu, C.-I. 1983b. Virility deficiency and the sex-ratio trait in Drosophila pseudoobscura. II. Multiple mating and overall virility selection. Genetics, 105, 663-679. 